\title{
A Millimeter-Scale Electric Generator
}

\author{
Matthew K. Senesky, Member, IEEE, and Seth R. Sanders, Member, IEEE
}

\begin{abstract}
The research presented in this paper concerns the design, construction, and testing of an electrical generator intended for interface with a MEMS internal combustion Wankel engine. The engine and the generator are integrated into a single unit by utilizing the engine rotor as the generator rotor. The design allows for thermal insulation between the stator and the combustion chamber, simple assembly of the engine and the generator, and excellent utilization of copper in the generator winding. The majority of the generator structure is built from discrete millimeter-scale components, with only the rotor being microfabricated. Prototype construction and testing are described; a peak open-circuit voltage of $2.63 \mathrm{~V}$ and a maximum power output of $375 \mu \mathrm{W}$ at $13.3 \mathrm{kr} / \mathrm{m}$ are reported.
\end{abstract}

Index Terms-Engines, microelectromechanical devices, mobile power supplies, permanent magnet generators.

\section{INTRODUCTION}

A S THE SIZE and the weight of portable electronic devices are increasingly dominated by electrochemical batteries, there is a growing demand for smaller and lighter power systems with outputs ranging from microwatts to tens of watts. At the low end of this range, demand is driven by wireless sensor networks and MEMS robots; at the high end, demand is driven by consumer electronics such as mobile phones and computing and by military applications such as unattended ground sensors, unmanned aerial vehicles, and electronic systems carried by soldiers [1].

The dominant technology for these applications is the electrochemical battery. Of commercially available battery types, lithium-thionyl chloride $\left(\mathrm{Li}-\mathrm{SOCl}_{2}\right)$ has the highest specific energy among primary batteries at present $(660 \mathrm{Wh} / \mathrm{kg})$, whereas lithium-sulfur ( $\mathrm{Li}-\mathrm{S})$ leads among secondary batteries $(370 \mathrm{Wh} / \mathrm{kg}$ ) [2]. An obvious set of candidates for energy storage with higher levels of specific energy are hydrocarbon fuels, which are long used in transportation applications for just this reason. Octane, for example, has specific energy of $12.3 \mathrm{kWh} / \mathrm{kg}$ [3], which is roughly 18 times that of $\mathrm{Li}-\mathrm{SOCl}_{2}$ batteries and 33 times that of Li-S batteries. Of course, chem-

Paper IPCSD-07-111, presented at the 2004 Industry Applications Society Annual Meeting, Seattle, WA, October 3-7, and approved for publication in the IEEE TRANSACTIONS ON INDUSTRY APPLICATIONS by the Electric Machines Committee of the IEEE Industry Applications Society. Manuscript submitted for review August 31, 2004 and released for publication November 27, 2007. Published July 23, 2008 (projected). This work was supported by the Defense Advanced Research Projects Agency under Contract NBCHC010060.

M. K. Senesky is with Tesla Motors, Inc., San Carlos, CA 94070 USA (e-mail: senesky@gmail.com).

S. R. Sanders is with the Department of Electrical Engineering and Computer Sciences, University of California, Berkeley, CA 94720 USA (e-mail: sanders@eecs.berkeley.edu).

Color versions of one or more of the figures in this paper are available online at http://ieeexplore.ieee.org.

Digital Object Identifier 10.1109/TIA.2008.926291 ical to thermal, thermal to mechanical, and mechanical to electrical conversion efficiencies must be taken into account in considering hydrocarbon fuels for electricity production. However, a $10 \%$ overall conversion efficiency still results in a higher specific energy than the best available batteries.

Several recent research efforts have sought to capitalize on the high specific energy of chemical fuels through the use of internal combustion (IC) engines paired with electrical generators (see [4] and [5] and its references). This approach leverages the specific energy of hydrocarbon fuels as well as the high power density of IC engines. However, producing such a system to run efficiently on the millimeter- or microscale poses considerable challenges in thermal and fluid management, combustion processes, and electromechanical energy conversion.

The contribution of the research presented in this paper is in the design, construction, and testing of an electrical generator intended for interface with a MEMS IC engine. The majority of the generator structure is built from discrete millimeter-scale parts, with only the rotor being microfabricated. We believe that this approach offers superior performance as compared with the purely microfabricated generators for power outputs on the order of milliwatts and above-at these power levels, existing microfabrication techniques do not allow for the deposition of sufficient volumes of soft magnetic or electrically conductive material.

The IC engine intended as the prime mover for the generator is a microfabricated Wankel engine [3], [6]. The engine and the generator are integrated into a single unit by mounting the generator stator to the silicon engine housing and by utilizing the engine rotor as the generator rotor. This is achieved by electroplating nickel-iron poles into the rotor tips. Integration of the engine and the generator avoids shaft coupling between the two machines, simplifying the assembly of the devices, improving the sealing of the engine housing, and reducing unwanted heat flow out of the combustion chamber. It also, however, places unique constraints on the generator design, as detailed in Section II.

\section{DESIGN}

The generator configuration shown in Figs. 1 and 2 was developed in response to the two major constraints: the unusual Wankel rotor geometry, which is not well suited to a radial flux design, and the high temperature of the combustion chamber $\left(300^{\circ} \mathrm{C}\right)$, which makes a permanent-magnet rotor impractical. The generator could be described as an axial-flux circumferential current permanent-magnet machine, although we note significant differences with the design presented in [7]. The configuration might best be described as an axial-flux clawpole stator machine, which is similar to radial flux designs 


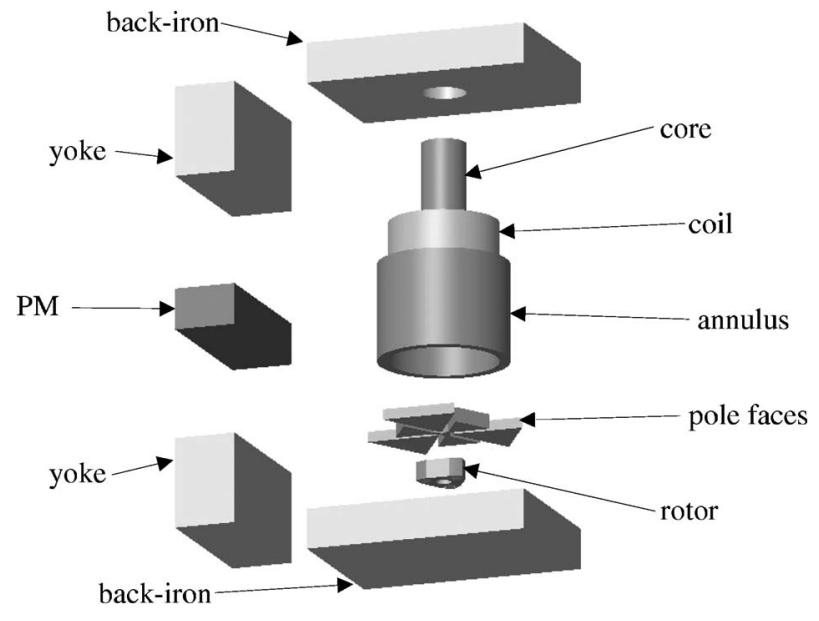

Fig. 1. Generator assembly (engine housing suppressed for clarity).

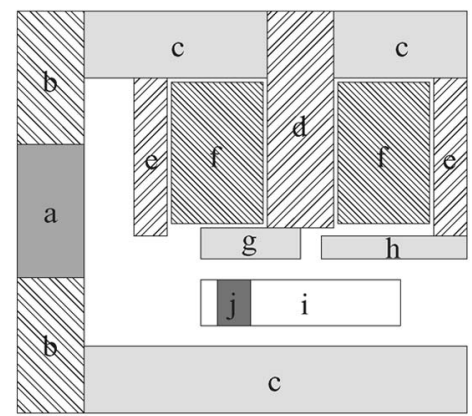

\begin{tabular}{lcc}
\hline a. & Permanent magnet & Bonded NdFeB \\
b. & Magnet yoke & Low-carbon steel \\
c. & Back-iron & Powdered iron \\
d. & Center post & Silicon Steel \\
e. & Annulus & Silicon Steel \\
f. & Winding & Copper \\
g. & Center-connected pole face & Powdered iron \\
h. & Edge-connected pole face & Powdered iron \\
i. & Rotor & Silicon \\
j. & Rotor pole & Nickel-iron \\
\hline
\end{tabular}

Fig. 2. Schematic cross section (not to scale). Part names and materials are also given.

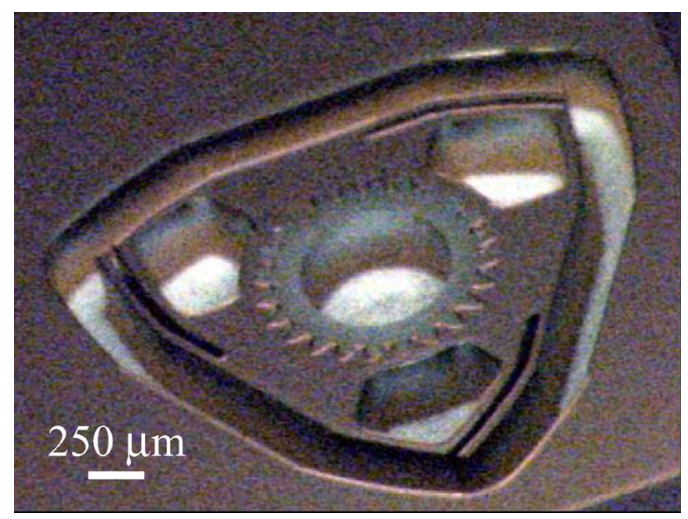

Fig. 3. Microfabricated Wankel rotor before electroplating.

with concentrated windings presented in [8] and [9]. The stator is a six-pole single-phase configuration, with the permanent magnet being part of the stator assembly. The flanged triangular rotor (shown in Fig. 3) has a soft magnetic pole in each of its

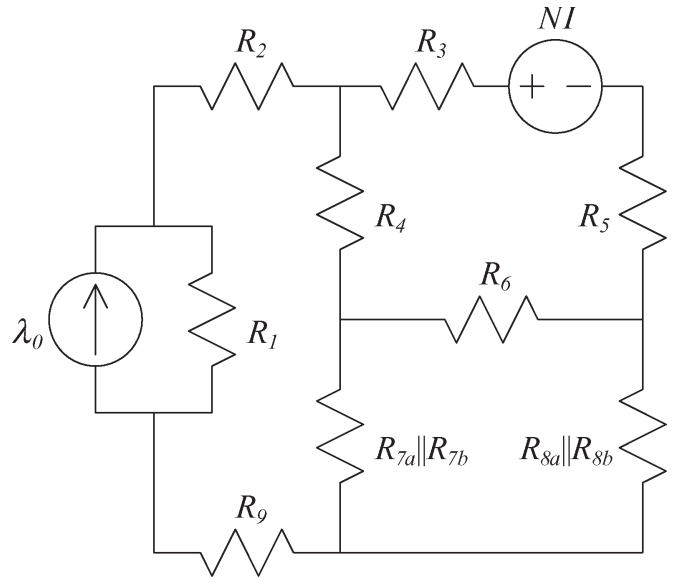

Fig. 4. Magnetic circuit model of the generator.

three tips. The design allows for thermal insulation between the stator and the combustion chamber, and it places the permanent magnet in a relatively low temperature location. The axial-flux configuration is insensitive to the shape of the rotor poles, and it allows simple assembly by sandwiching the engine housing between the upper and lower halves of the stator. The winding arrangement provides for excellent utilization of copper-there are no end turns, none of the dimensions of the coil are constrained by the rotor or permanent-magnet structures, and the winding resistance is independent of pole number. The inner diameter of the winding is determined only by the saturation and loss properties of the core material, whereas the outer diameter and length can be varied to meet the performance and size criteria.

\section{ANALYSIS}

Several aspects of the design pose obstacles to straightforward analysis. Flux in the generator travels in three dimensions - axially, radially, and circumferentially. Examination of any one cross section of the machine does not yield a complete picture of the flux paths. Care must be taken in formulating magnetic circuit and finite-element models to consider the generator as a 3-D whole. Note also that the motion of the Wankel rotor includes both rotation and a small eccentricity (i.e., translation in a circular trajectory). Because the eccentricity is much smaller than the rotor radius, the rotor motion is approximated as purely rotational. Perhaps most importantly, the generator is homopolar; the magnetic field in the gap changes in magnitude, but not polarity, as the rotor turns. This implies that performance will be sensitive to the saturation of the stator. If the bias field imposed on the stator by the permanent magnet is too large, the low incremental permeability of the stator components will reduce the ac flux linking the coil, resulting in a decrease in power output.

Fig. 4 shows a magnetic circuit model of the generator corresponding to the cross section of Fig. 2. The permanent magnet is represented by a flux source $\lambda_{\mathrm{o}}$ in parallel with a leakage reluctance $R_{1}$. The winding appears as an MMF source NI. Reluctance $R_{2}$ represents the top portion of the magnet yoke; $R_{3}$ represents the top portion of the back iron. Reluctance 


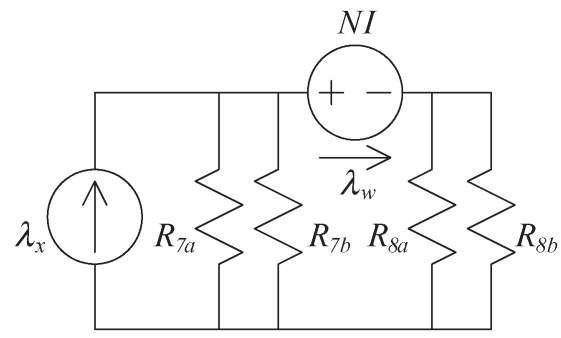

Fig. 5. Simplified magnetic circuit model, assuming high permeability in the soft magnetic components. Expressions for the reluctances are given in (1)-(4).

$R_{4}$ models the series combination of the annulus and the edgeconnected pole faces. Similarly, $R_{5}$ models the series combination of the center post and the center-connected pole faces. The pole-to-pole leakage path in the stator is represented by $R_{6}$. Reluctances $R_{7 \mathrm{a}}$ and $R_{7 \mathrm{~b}}$ model two paths from the edgeconnected pole faces to the lower back iron-one bypassing the rotor poles and one linking the rotor poles, respectively. Similarly, $R_{8 \mathrm{a}}$ and $R_{8 \mathrm{~b}}$ model flux paths from the centerconnected pole faces to the back iron. Expressions for $R_{7 \mathrm{a}}$, $R_{7 \mathrm{~b}}, R_{8 \mathrm{a}}$, and $R_{8 \mathrm{~b}}$ are given next. Finally, $R_{9}$ represents a series combination of the lower back iron and the lower magnet yoke, as well as the rotor shaft reluctance when the test rotor described in Section IV is in place.

For the purposes of design, extracting closed-form expressions from a magnetic circuit model with more than five or six elements can be unwieldy. To develop design intuition, a simpler model such as the one shown in Fig. 5 is useful. Here, high permeability is assumed in the soft magnetic materials, such that the air gaps dominate the design.

In defining the area and length parameters as in Figs. 6 and 7, the reluctances in Fig. 5 can be written as

$$
\begin{aligned}
R_{7 \mathrm{a}} & =\frac{\ell_{\mathrm{a}}}{\mu_{\mathrm{o}}\left(A_{z}-A_{x}\left(1-\left(\theta \frac{P}{2 \pi}\right)\right)\right)} \\
R_{7 \mathrm{~b}} & =\frac{\ell_{\mathrm{a}}-\ell_{\mathrm{b}}}{\mu_{\mathrm{o}} A_{x}\left(1-\left(\theta \frac{P}{2 \pi}\right)\right)} \\
R_{8 \mathrm{a}} & =\frac{\ell_{\mathrm{a}}}{\mu_{\mathrm{o}}\left(A_{y}-A_{x} \theta \frac{P}{2 \pi}\right)} \\
R_{8 \mathrm{~b}} & =\frac{\ell_{\mathrm{a}}-\ell_{\mathrm{b}}}{\mu_{\mathrm{o}}\left(A_{x} \theta \frac{P}{2 \pi}\right)}
\end{aligned}
$$

where $P$ is the number of poles, and the rotor angle $\theta$ varies from 0 to $(2 \pi / P)$. Note that in this simple model, the parallel combination of all four reluctances does not depend on the rotor position $\theta$, and the leakage reluctance across the permanent magnet is large compared with the gap reluctance. Hence, the use of a constant flux source $\lambda_{x}$ is justified.

From (1)-(4) and Figs. 5-7, the operation of the generator is apparent. As the rotor turns, the flux from the permanent magnet is directed either around the outside of the winding or through its center. This changing flux linkage through the winding generates the back-electromotive-force (EMF) voltage.

Not only is the back-EMF voltage intuitive and easy to compute, but it can be shown that for an ideal machine under steady-state conditions, the back-EMF constant is equal to the

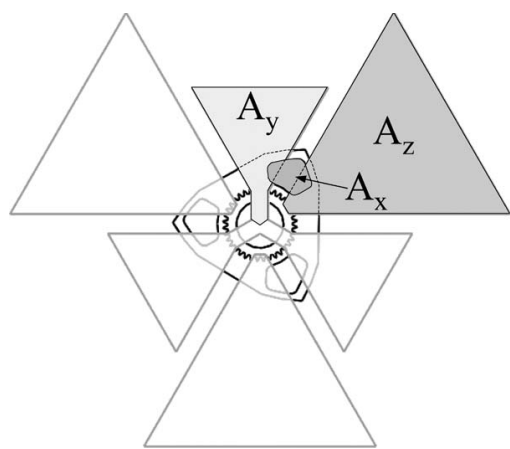

Fig. 6. Pole-area parameter definitions. The figure shows a plan view of the stator pole faces and the rotor.

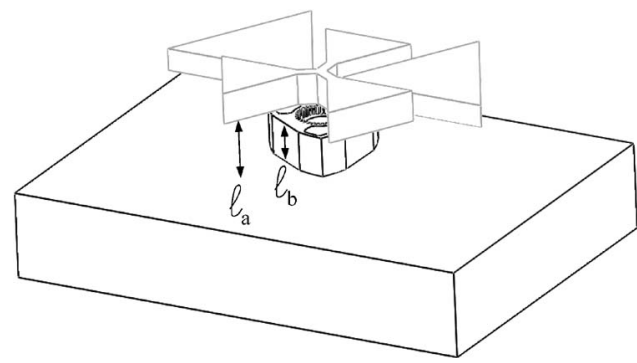

Fig. 7. Length parameter definitions. The figure shows a perspective view of the stator pole faces, rotor, and back iron. Note that one stator pole face has been suppressed for clarity.

torque constant [10]. Thus, the torque should be proportional to the back EMF per turn, and the back-EMF expression reveals a great deal about the design. From Fig. 5, we have

$$
\lambda_{\mathrm{w}}=\frac{R_{7 \mathrm{a}} \| R_{7 \mathrm{~b}}}{\left(R_{7 \mathrm{a}} \| R_{7 \mathrm{~b}}\right)+\left(R_{8 \mathrm{a}} \| R_{8 \mathrm{~b}}\right)} \lambda_{x}
$$

and substituting from (1)-(4)

$$
\lambda_{\mathrm{w}}=\frac{\ell_{\mathrm{b}} A_{x} \theta+\left(\ell_{\mathrm{a}}-\ell_{\mathrm{b}}\right) A_{y}}{\ell_{\mathrm{b}} A_{x}+\left(\ell_{\mathrm{a}}-\ell_{\mathrm{b}}\right)\left(A_{y}+A_{z}\right)} \lambda_{x}
$$

gives the flux linking the winding $\left(\lambda_{\mathrm{w}}\right)$. Taking the derivative with respect to time gives the back EMF

$$
V_{\mathrm{o}}=\frac{\ell_{\mathrm{b}} A_{x}}{\ell_{\mathrm{b}} A_{x}+\left(\ell_{\mathrm{a}}-\ell_{\mathrm{b}}\right)\left(A_{y}+A_{z}\right)} \lambda_{x} \cdot \omega .
$$

Examining (7), we see that a large ratio of $\ell_{\mathrm{b}}$ to $\left(\ell_{\mathrm{a}}-\ell_{\mathrm{b}}\right)$ (i.e., a small gap) is desirable, as is a rotor pole area $A_{x}$ that is equal in size to the stator pole areas $A_{y}$ and $A_{z}$.

By using the circuit in Fig. 5, an expression for torque can also be derived. One approach is to calculate the coenergy in the gap and then take the derivative of the coenergy with respect to the rotor angle to obtain torque. Note that since the flux in the permanent magnet is assumed to be constant, its contribution to the change in coenergy can be neglected. Coenergy in the soft magnetic components is small due to the materials' high permeability, and it is also neglected.

Equation (8) gives an expression for the torque produced by a generator with $P$ poles and winding current NI. The flux density in the rotor due only to the permanent magnet $\left(B_{\mathrm{pm}}\right)$ is assumed in the model to be independent of the rotor 
position; hence, it is simpler to formulate (8) in terms of this quantity rather than $\lambda_{x}$. The first term in square brackets is the torque due to Lorentz forces, whereas the second term is due to reluctance forces. For moderate winding currents, the reluctance forces are small compared with the Lorentz forces, and the torque can be approximated for initial design purposes by the Lorentz expression only. The absence of a term involving $B_{\mathrm{pm}}^{2}$ indicates that this model predicts zero cogging torque

$$
\begin{aligned}
\tau= & {\left[\frac{P^{2}}{4 \pi}\left(\frac{\ell_{\mathrm{b}}}{\ell_{\mathrm{a}}}\right) A_{x} B_{\mathrm{pm}} \mathrm{NI}\right]+\left[\frac{\mu_{\mathrm{o}} P^{2}}{\pi^{2}}\left(\frac{\ell_{\mathrm{b}}}{\ell_{\mathrm{a}}}\right)\right] } \\
& \cdot\left[\frac{A_{x}\left\{\left(\ell_{\mathrm{a}}-\ell_{\mathrm{b}}\left(A_{y}-A_{z}\right) \pi+\ell_{\mathrm{b}} A_{x}(\theta P-\pi)\right\}\right.}{\left(\ell_{\mathrm{a}}-\ell_{\mathrm{b}}\right)\left\{\left(\ell_{\mathrm{a}}-\ell_{\mathrm{b}}\right)\left(A_{y}+A_{z}\right)+\ell_{\mathrm{b}} A_{x}\right\}}(\mathrm{NI})^{2}\right] .
\end{aligned}
$$

Equation (8) gives intuition into the possibility of increasing the torque in the machine. Larger rotor pole area, a thicker rotor, and high flux densities all offer a linear increase in torque. Note however that the torque increases with the square of the number of poles. Furthermore, because the generator winding resistance is independent of the pole number, the only limits on the number of poles come from practical limits on the minimum gap size (and, hence, the pole arc length at which fringing begins to dominate) and higher core loss due to higher electrical frequencies. In the design presented here, a six-pole configuration was chosen to coincide with the triangular shape of the Wankel rotor.

While (7) and (8) are useful in providing design intuition, an accurate analysis is provided by numerical solution of the detailed magnetic circuit model of Fig. 4, using finite values for $R_{1}, R_{2}, R_{3}, R_{4}, R_{5}, R_{6}$, and $R_{9}$. As previously noted, the homopolar nature of the design makes the generator output sensitive to saturation effects. These effects are difficult to calculate by hand; to more accurately model the saturation and fringing effects, finite-element analysis (FEA) can be applied with appropriate saturation characteristics for the soft magnetic materials.

With modest computing resources, nonlinear 3-D FEA can be difficult. Hence, a series of 2-D finite-element models was developed, as shown in Fig. 8. The figure shows four axisymmetric magnetostatic models, representing cross sections through two different $r-z$ planes of the generator, at two different rotor positions. In Fig. 8(a), the cross section is taken through a center-connected pole, with the rotor in an aligned position. Fig. 8(b) shows a cross section through an edgeconnected pole at the same rotor position. Fig. 8(c) and (d) shows the same cross sections for the complementary rotor position, where the rotor is aligned with the edge-connected pole face.

The relative permeability functions used for the powdered iron and silicon steel materials, respectively, were

$$
\begin{aligned}
\mu_{\text {powder }} & =\frac{75}{1+25 \cdot|B|^{2}}+1 \\
\mu_{\text {steel }} & =\frac{26.5 \times 10^{3}}{1+25 \cdot|B|^{2}}+1 .
\end{aligned}
$$

(a)

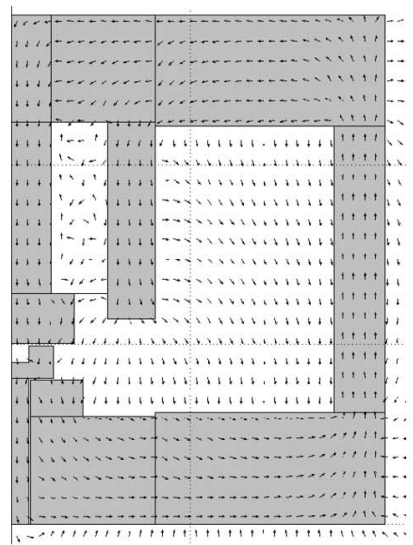

(c)

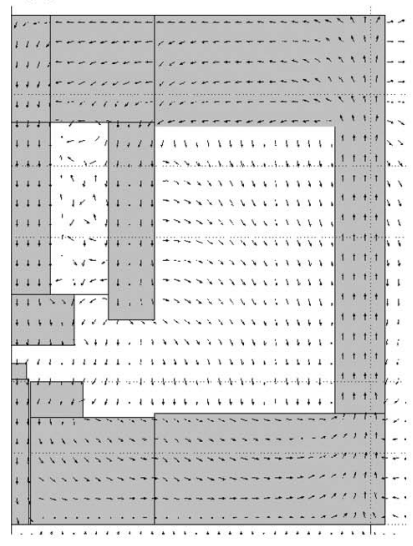

(b)

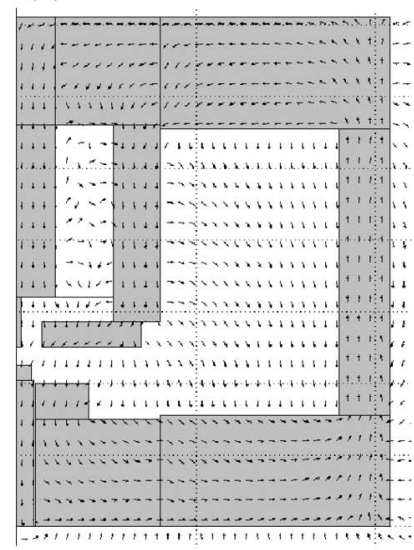

(d)
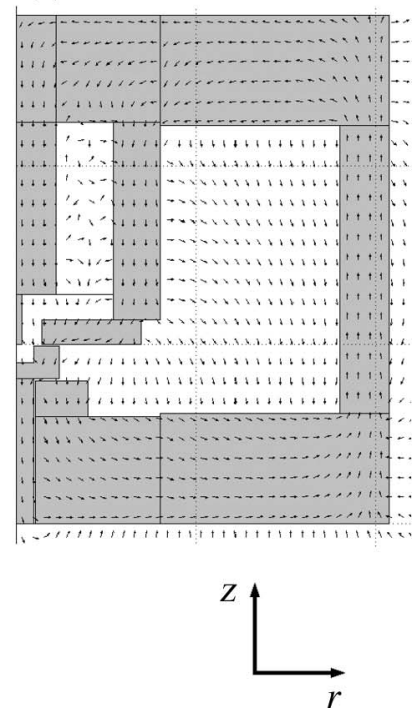

Fig. 8. Axisymmetric finite-element models, using the steel test rotor. The left side of each model is the axis of symmetry. Plotted are arrows indicating the direction of B field. Note that arrows are of equal length and do not indicate the magnitude of the flux. The random orientation of the vector field in the winding area is due to the numerical noise in an area of near zero flux.

From the FEA solutions, values for the relative permeability in each of the soft magnetic components can be determined. Because of their implicit axisymmetry, no model captures the exact operating point of the generator. However, interpolating between Fig. 8(a) and (b) and Fig. 8(c) and (d) can give estimates of the level of saturation and appropriate $\mu_{\mathrm{r}}$ values for rotor positions $\theta=(\pi / 3)$ and $\theta=0$, respectively.

By substituting these permeabilities into the magnetic circuit model of Fig. 4, flux linking the winding can be determined for the two rotor positions. By assuming these values to be the maximum and minimum of a sinusoidally varying flux, the back EMF can be estimated. Using this method, we calculate a backEMF amplitude of $218((\mathrm{nV} \cdot \mathrm{s}) /(\mathrm{rad} \cdot \mathrm{turn}))$.

\section{Construction}

A prototype has been constructed; the upper portion of the stator is shown in Fig. 9. Different soft magnetic materials were used for the various stator components, according to their particular requirements. The stator pole faces are made from 


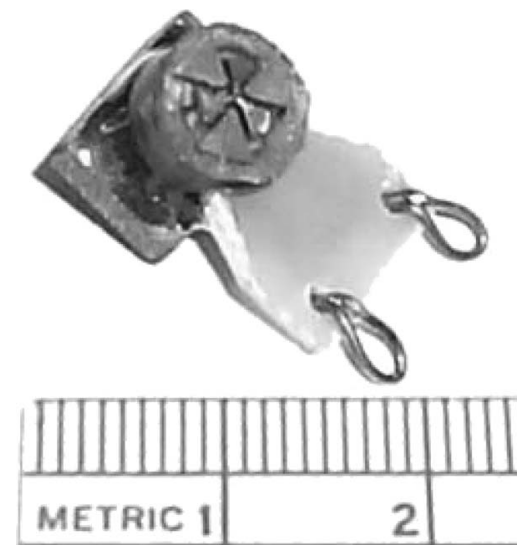

Fig. 9. Partial stator assembly; back iron and permanent magnet are not shown.

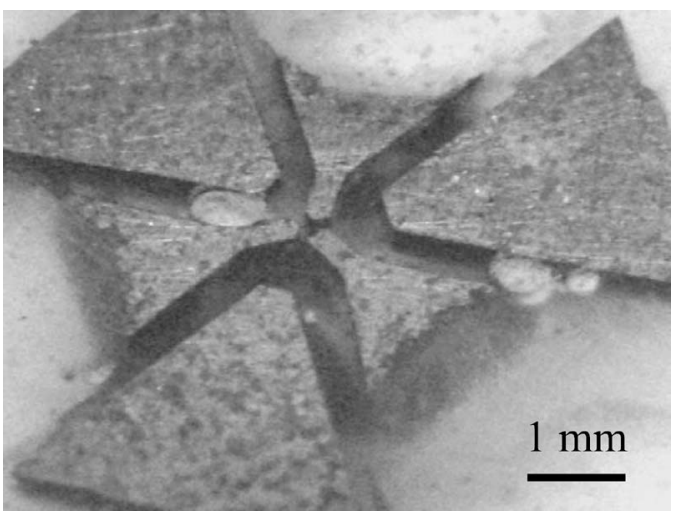

Fig. 10. Powdered iron stator pole faces potted in epoxy.

powdered iron material (Micrometals' “-26” material [11]). This material was selected for its low loss, high saturation flux density, and isotropic properties. Due to their fine feature sizes, the stator pole faces were formed by electrical discharge machining. The stator pole faces were positioned with the help of a template and then potted together with epoxy. The potted stator pole faces are shown in Fig. 10. The powdered iron was also used for the top and bottom portions of the back iron, which is again due to its low loss and isotropic properties. These pieces were machined with conventional techniques.

In the center post and annulus portions of the stator, flux distribution is 1- or 2-D, and high permeability is desired. Sheets of silicon steel (Arnold's "Arnon 5" [12]) that are 0.005 in thick, with magnesium phosphate insulation, were used for these parts. The center post was formed by folding and compressing a single sheet of steel into a layered structure and then by grinding to its final shape. The annulus was formed into a roll and secured with epoxy, and the ends were milled to a final dimension. Both parts were then etched with dilute nitric acid in a 1:1 ratio of $\mathrm{HNO}_{3}: \mathrm{H}_{2} \mathrm{O}$ for $10 \mathrm{~s}$ to discourage edge-to-edge conduction between laminations. The center post was polished with fine-grain sandpaper before assembly. The finished center post and annulus appear in Figs. 11 and 12, respectively. The winding consists of 4200 turns of 50 AWG wire on a plastic bobbin that encloses the center post and fits inside the annulus.

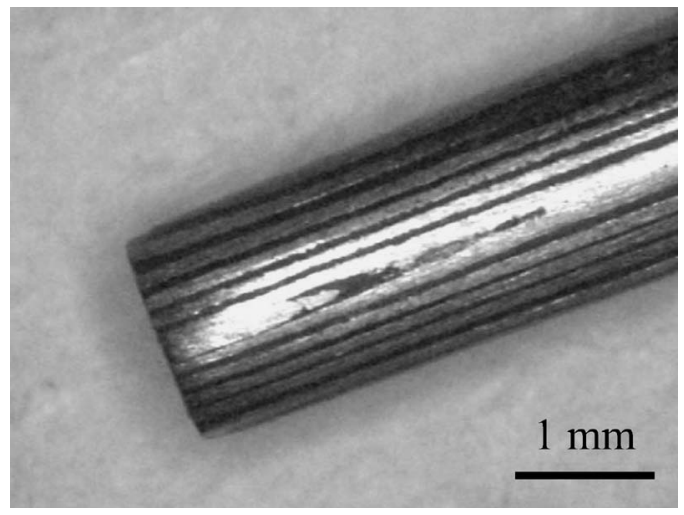

Fig. 11. Laminated silicon steel center post after etching and polishing.

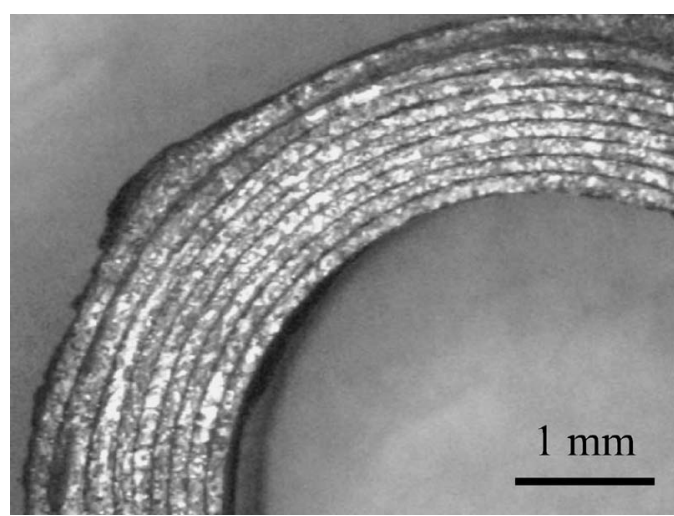

Fig. 12. Laminated silicon steel annulus after etching.

The permanent magnet was machined from bonded NdFeB ("Neoform" from Dexter Magnetic Technologies [13]) and then magnetized. Due to the sensitivity of the generator design to the saturation effects, a fixture was made to hold the permanent magnet and its two yoke pieces. The fixture allows the magnet to be gradually removed from the yoke by turning a screw. Thus, the optimal amount of excitation can be determined experimentally.

The silicon rotor was fabricated in the UC Berkeley Microlaboratory, as described in [14]. The process begins with a $500-\mu \mathrm{m}$ silicon wafer. Trenches are etched in the shape of the rotor poles. The wafer is then bonded to a second wafer which has a copper seed layer, and the wafer stack is electroplated with a 50:50 ratio of nickel to iron. This composition was selected to satisfy both curie temperature $\left(350{ }^{\circ} \mathrm{C}\right.$, as given in [15]) and thermal expansion constraints. The top surface of the plated wafer is planarized, the seed wafer is removed, and the remaining features of the rotor are etched by using deep reactive ion etching.

Because the development of the MEMS Wankel engine has proceeded in parallel with the generator development, an electroplated silicon rotor was not available for generator testing at the time of writing. Hence, a solid steel rotor (Fig. 13) was machined with salient pole shapes roughly matching those of the silicon Wankel rotor (Fig. 3). This test rotor has a shaft to allow the spinning of the rotor with an external electric motor. 


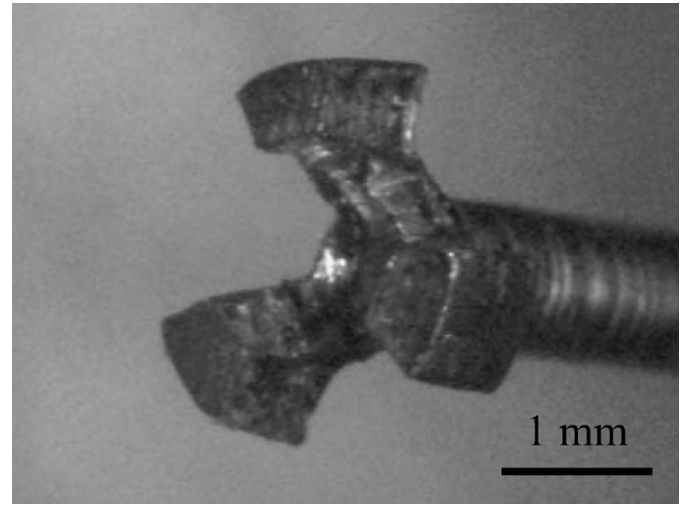

Fig. 13. Steel test rotor. The salient poles are intended to roughly match the size and the shape of the pole areas in Fig. 3.

TABLE I

GENERATOR PARAMETERS

\begin{tabular}{ccc}
\hline Quantity & Calculated* & Measured \\
\hline$K_{v}$ & $218 \frac{\mathrm{nV} \cdot \mathrm{s}}{\mathrm{rad} \cdot \text { turn }}$ & $147 \frac{\mathrm{nV} \cdot \mathrm{s}}{\mathrm{rad} \cdot \mathrm{turn}}$ \\
$V_{o}$ & $3.84 \mathrm{~V}$ & $2.63 \mathrm{~V}^{* *}$ \\
$R_{w}$ & $1.92 \mathrm{k} \Omega$ & $1.95 \mathrm{k} \Omega^{\dagger}$ \\
$L_{w}$ & $76-101 \mathrm{mH}$ & $294-310 \mathrm{mH}^{\dagger \ddagger}$ \\
$P_{\text {out }, \text { max }}$ & $947 \mu \mathrm{W}$ & $375 \mu \mathrm{W}^{\natural}$ \\
\hline
\end{tabular}

* Calculations assume $\mathrm{f}=667 \mathrm{~Hz}$.

** Measured at $677 \mathrm{~Hz}$. See Fig. 14.

$\dagger$ Measured at $1 \mathrm{kHz}$.

$\ddagger L_{w}$ varies depending on $\theta$.

Measured at $\mathrm{f}=673 \mathrm{~Hz}, \mathrm{R}_{\text {load }}=2.72 \mathrm{k} \Omega$.

\section{Results}

The assembled generator was mounted on a test stand that allows the axial adjustment of gap length and the lateral adjustment of rotor position. After setting the gap length, lateral position was manually adjusted for maximum back EMF. As described in Section IV, permanent-magnet excitation was also manually adjusted to maximize the back EMF. Resistance and inductance measurements were then made with an $L C R$ meter at $120 \mathrm{~Hz}$ and $1 \mathrm{kHz}$. Measured and calculated values for the winding resistance $\left(R_{\mathrm{w}}\right)$, the winding inductance $\left(L_{\mathrm{w}}\right)$, the back-EMF constant $\left(K_{\mathrm{v}}\right)$, the open-circuit voltage $\left(V_{\mathrm{o}}\right)$, and the maximum power output $\left(P_{\text {out,max }}\right)$ are summarized in Table I.

The nominal speed of operation for the MEMS Wankel engine is a shaft speed of $40 \mathrm{kr} / \mathrm{m}$, which corresponds to a rotor speed of $13.3 \mathrm{kr} / \mathrm{m}$, and an electrical frequency of $667 \mathrm{~Hz}$. All the voltage and power measurements reported here were obtained by spinning the steel test rotor with an external dc electric motor at $13.3 \mathrm{kr} / \mathrm{m}$. Because the motor was operated without speed control, variation in the electrical frequency of about $2.5 \%$ was observed. In the following, the actual frequency of measurements has been noted where appropriate.

Experimental data showing the open-circuit voltage waveform across the generator terminals are shown in Fig. 14. The output has a magnitude of approximately $2.63 \mathrm{~V}$ at $677 \mathrm{~Hz}$. The subharmonic content is believed to be due to asymmetries in the rotor which cause variations in the waveform once per shaft rotation or every three electrical periods. A noticeable

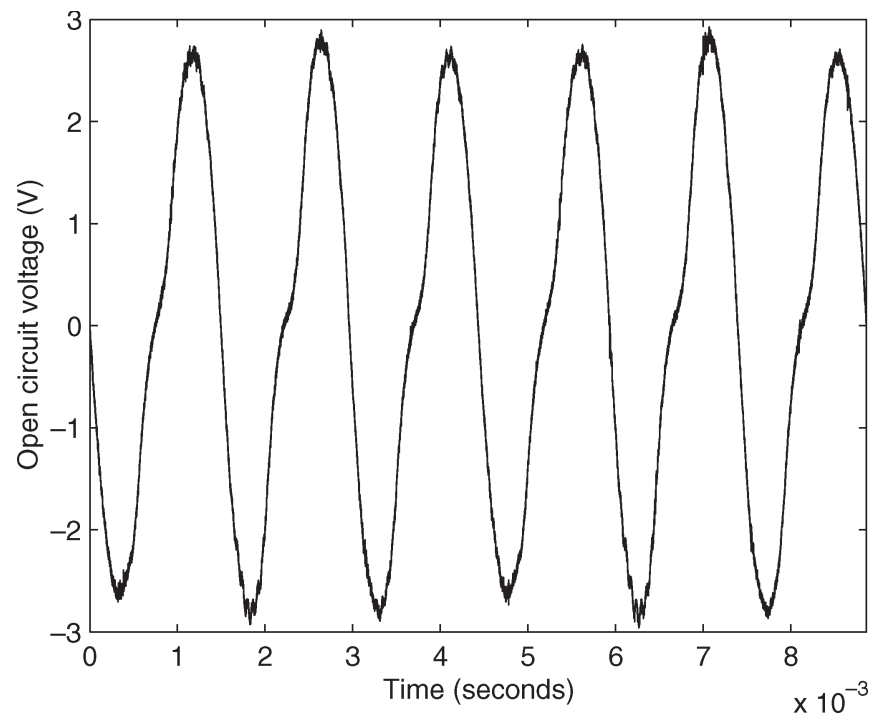

Fig. 14. Open-circuit output voltage, $f=677 \mathrm{~Hz}$. Peak voltage is approximately $2.63 \mathrm{~V}$.

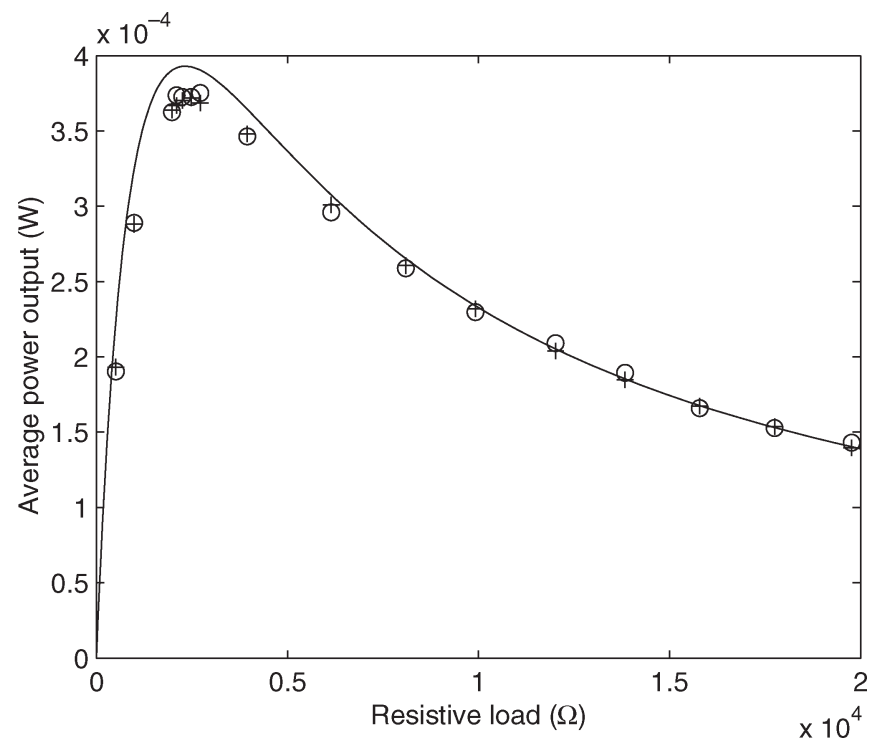

Fig. 15. Average power output versus load resistance. The circles (o) are measured data points, the plus signs $(+)$ are measured data rescaled to account for frequency variation, and the solid line $(-)$ is the calculated result using the measured values from Table I. The maximum measured power output is $375 \mu \mathrm{W}$.

second harmonic is also present, which is most likely due to the different shapes of the center- and edge-connected stator pole faces.

Fig. 15 shows the average power output as a function of load resistance. The plot shows experimental data, as well as a calculated curve based on the measured values in Table I. Because of the frequency variation present in the data, values rescaled to $667 \mathrm{~Hz}$ were also plotted, showing the results for constant frequency. The maximum measured power output was $375 \mu \mathrm{W}$, which was achieved at $673 \mathrm{~Hz}$ with a load of $2.72 \mathrm{k} \Omega$.

We note that the calculated and measured values in Table I are not closely matched. This is due to the high sensitivity of the design to material saturation and the difficulty in obtaining 
a finite-element model that encompassed the entire structure of the device. A full 3-D FEA, while cumbersome for iterative design techniques, would likely yield more accurate predictions of performance.

\section{CONCLUSION}

A novel electric generator design has been presented. The design is intended to interact with a planar MEMS IC engine, and hence, many design choices were guided by the engine configuration. The resulting structure has several interesting features, most notably ample space for windings, and power output that scales with pole number.

The construction of a prototype was described. Experimental results show a peak open-circuit voltage of $2.63 \mathrm{~V}$ attained at a frequency of $677 \mathrm{~Hz}$, and a maximum average power output of $375 \mu \mathrm{W}$ into a $2.72-\mathrm{k} \Omega$ resistive load at $673 \mathrm{~Hz}$.

It is clear that the homopolar nature of the design limited the magnitude of the ac flux linking the stator winding. Although impractical for the application requirements previously presented, a similar design with a permanent-magnet rotor would likely be advantageous where appropriate. The fully reversing flux of such a design should provide a factor-of-two increase in flux linkage, with a further increase made possible by more closely approaching the stator material saturation. Furthermore, analysis indicates that the power output should increase as the square of the number of poles within certain practical limits. Compelling research opportunities exist in the use of the axial-flux claw-pole stator configuration with a high energy product permanent-magnet rotor.

\section{REFERENCES}

[1] National Research Council, "Energy-efficient technologies for the dismounted soldier," Nat. Academy Press, Washington, DC, Tech. Rep., 1997.

[2] T. R. Crompton, Battery Reference Book. Oxford, U.K.: Reed Educational Prof. Publishing, 2000.

[3] A. J. Knobloch, "Ultra-deep reactive ion etching for silicon Wankel internal combustion engines," Ph.D. dissertation, Univ. California, Berkeley, CA, 2003.

[4] A. H. Epstein et al., "Power MEMS and microengines," in Proc. IEEE Int. Conf. Solid-State Sens. Actuators (TRANSDUCERS), 1997, vol. 2, pp. 753-756.

[5] A. C. Fernandez-Pello, "Micropower generation using combustion: Issues and approaches," Proc. Combustion Inst., vol. 29, no. 1, pp. 883-899, 2002.

[6] K. Fu et al., "Design and fabrication of a silicon-based MEMS rotary engine," in Proc. ASME Int. Mech. Eng. Congr. Expo., 2001, vol. 2, pp. 3447-3452.

[7] J. Luo, D. Qin, T. A. Lipo, S. Li, and S. Huang, "Axial flux circumferential current permanent magnet (AFCC) machine," in Conf. Rec. IEEE Ind. Appl. Soc. Annu. Meeting, 1998, vol. 1, pp. 144-151.
[8] J. Cros, J. R. Figueroa, and P. Viarouge, "BLDC motors with surface mounted PM rotor for wide constant power operation," in Conf. Rec. IEEE Ind. Appl. Soc. Annu. Meeting, 2003, vol. 3, pp. 1933-1940.

[9] J. Wang, W. Wang, G. W. Jewell, and D. Howe, "Design optimisation of a miniature multi-pole permanent magnet generator," in Proc. 9th Int. Conf. Elect. Mach. Drives, 1999, pp. 128-132.

[10] J. R. Hendershot and T. J. E. Miller, Design of Brushless PermanentMagnet Motors. New York: Oxford Univ. Press, 1994.

[11] "Iron powder cores for power conversion and line filter applications," Product Catalog, Micrometals, Inc., Anaheim, CA, 2003. [Online]. Available: www.micrometals.com

[12] "Precision rolled strip \& foil," Product Catalog, Arnold, New York, 2003. [Online]. Available: www.arnoldmagnetics.com

[13] "Neoform material properties," Product Data Sheet, Dexter Magn. Technol., Inc., Fremont, CA. [Online]. Available: www.dextermag.com

[14] A. J. Knobloch, M. Wasilik, C. Fernandez-Pello, and A. P. Pisano, "Micro internal-combustion engine fabrication with $900 \mu \mathrm{m}$ deep features via DRIE," in Proc. ASME Int. Mech. Eng. Congr. Expo., 2003, vol. 5, pp. $115-123$.

[15] R. M. Bozorth, Ferromagnetism. New York: Van Nostrand, 1951.

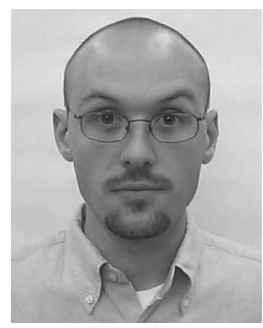

Matthew K. Senesky (S'03-M'05) received the A.B. and B.E. degrees from Dartmouth College, Hanover, NH, in 1998 and 1999, respectively, and the M.S. and Ph.D. degrees from the University of California, Berkeley, in 2003 and 2005, respectively.

From 2004 to 2007, he was with Artificial Muscle, Inc., where he worked on power electronics and actuator modeling for dielectric elastomer actuators. Since 2007, he has been with Tesla Motors, Inc., San Carlos, CA, developing motor-drive inverters for high-performance electric vehicles.

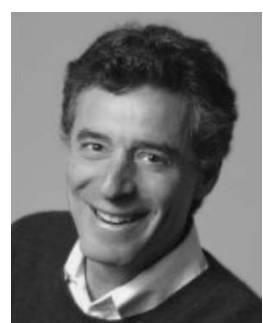

Seth R. Sanders (M'87-S'88-M'88) received the B.S. degree in electrical engineering and physics and the M.S. and Ph.D. degrees in electrical engineering from the Massachusetts Institute of Technology, Cambridge, in 1981, 1985, and 1989, respectively.

$\mathrm{He}$ was a Design Engineer with the Honeywell Test Instruments Division, Denver, CO. Since 1989, he has been with the Department of Electrical Engineering and Computer Sciences, University of California, Berkeley, where he is currently a Professor. He is currently actively supervising research projects in the areas of renewable energy, novel electric machine design, and digital pulsewidth-modulation strategies and associated IC designs for power conversion applications. During the 1992-1993 academic year, he was on an industrial leave with National Semiconductor, Santa Clara, CA. His research interests include high-frequency power conversion circuits and components, design and control of electric machine systems, and nonlinear circuit and system theory as related to the power electronics field.

Dr. Sanders has served as Chair of the IEEE Technical Committee on Computers in Power Electronics and as a Member-At-Large of the IEEE PELS AdCom. He was the recipient of the NSF Young Investigator Award in 1993 and multiple Best Paper Awards from IEEE Power Electronics and IEEE Industry Applications Societies. 